\title{
ESTADO IMUNITĀRIO RELATIVO À POLIOMIELITE DAS CRIANÇAS DE 0-12 ANOS, RESIDENTES NO MUNICIPIO DE SÃO PAULO, BRASIL E ASSISTIDAS PELO HOSPITAL MENINO JESUS
}

\begin{abstract}
Barbosa, V. \& Stewien, K.E. - Estado imunitário relativo à poliomielite das crianças de 0-12 anos, residentes no município de São Paulo, Brasil e assistidas pelo Hospital Menino Jesus. Rev. Saúde públ, S. Paulo, 9:137-53, 1975.
\end{abstract}

RESUMo: A prevalencia dos anticorpos neutralizantes contra os três tipos de poliovirus e os niveis de imunidade para diferentes grupos etários foram determinados, através de um inquérito soro-epidemiológico, numa população de crianças de 0-12 anos de idade, residentes no município de São Paulo, Brasil $e$ assistidas pelo Hospital Menino Jesus. Os resultados mostraram um número elevado de crianças suscetiveis à infecçäo por poliovírus no primeiro ano de vida, particularmente no grupo etário de 9-12 meses, em que a proporçâo de crianças completamente desprotegidas (triplo-suscetiveis) alcançou 42,5\%. Neste grupo, a prevaléncia de anticorpos dos tipos 1,2 e 3 foi apenas em torno de 40\%. Dentre as crianças do grupo etário de $0-5$ anos, que receberam três ou mais doses de vacina oral trivalente, verificou-se a baixa proporção de $60 \%$ de duplo mais triplo-imunes. Os resultados mostraram que o estado imunitário das crianças deste grupo foi o mesmo nas três zonas geográficas da Capital, sendo em torno de apenas 50\% a proporção de crianças duplo mais triploimunes. Estes resultados indicam níveis precários de imunidade, particularmente nas crianças do primeiro ano de vida. Existe, pois, uma necessidade evidente de realizar novos inquéritos sorológicos, além de intensificar e meThorar a vacinação de manutenção contra a poliomielite em nosso meio.

UNItermos: Poliomielite. Imunidade. Inquérito Epidemiológico. São Paulo, Brasil. Poliovirus.

\section{N T R O D U C Ȧ O}

Sabin, baseado em estudos preliminares conduzidos em diferentes partes do mundo, previu que pelo uso da vacina oral inicialmente em campanhas de vacinação em massa e, posteriormente, nas novas gerações de suscetíveis, seria possível controlar e, até mesmo, erradicar a poliomielite. Esta previsão tornou-se realidade em todos os lugares nos quais a vacinação foi adequada e sistematicamente conduzida $10,22,23,2 \pi, 40.41,43,45,46,47$, i1, $\overline{3}, \overline{1}$, .

* Do Departamento de Epidemiologia da Faculdade de Saúde Pública da USP — Av. Dr. Arnaldo, 715 - São Paulo, SP - Brasil

** Do Departamento de Microbiologia e Imunologia do Instituto de Ciências Biomédicas da USP - Av. Dr. Arnaldo, 715 - São Paulo, SP - Brasil 
BARBOSA, V. ¿ STEWIEN, K.E. - Estado imunitário relativo à poliomielite das criancas de 0-12 anos, residentes no municipio de São Paulo, Brasil e assistidas pelo Hospital Menino Jesus. Rev. Saude públ., S. Paulo, 9:137-53, 1975.

O objetivo do uso da vacina de vírus vivos atenuados não é de apenas proteger um grande número de indivíduos contra a doença, o que também pode ser alcançado mediante a vacina de vírus inativados de Salk, mas é, sobretudo, o de interromper a cadeia de transmissão dos poliovírus naturais, de modo que a doença possa ser efetivamente controlada ou até mesmo erradicada de populações extensas. Tal sucede quando uma certa proporção dos individuos suscetíveis é imunizada, porque a vacina oral, além de induzir nos indivíduos a formação de anticorpos protetores no sangue, confere-lhes resistência intestinal contra as infecções com poliovírus naturais, deixando estes indivíduos de constituir elos na cadeia de transmissão da poliomielite ${ }^{44,45}$.

Decorre daí, logicamente, que o princípio epidemiológico fundamental para controlar a doença se baseia "na saturação" das comunidades pelos vírus vacinais, em espaço de tempo o mais breve possível. Tanto isso é verdadeiro, que Sabin ${ }^{44}$ afirma textualmente: "Tornouse evidente que a melhor maneira de alcançar o desejável rompimento na cadeia de transmissão dos poliovírus naturais foi a de realizar campanhas de vacinação em massa, a fim de envolver, em curto espaço de tempo, pelo menos $75 \%$ dos grupos etários mais sucetíveis".

Problemas com a eficiência da vacinação oral foram, entretanto, encontrados em países de clima tropical e subtropical, devido a fatores de ordem epidemiológica e administrativa. Entre os primeiros, ressalta a interferência que sofrem os vírus vacinais na mucosa intestinal, em presença de enterovírus dos grupos Echo e Coxsackie $^{16,39}$ e 50. Este fenômeno, particularmente observado nas crianças de 0 a 5 anos de idade, adquire especial significado prático nas regióes de clima quente, tendo investigações virológicas evidenciado taxas de eliminação de enterovírus de até $80 \%$ a $90 \%$ em crianças dessa idade ${ }^{11}$. Por outro lado, estudos sorológicos mostraram, nessas áreas, uma queda na proporção das taxas de soroconversão para apenas $33 \%$ dos vacinados ${ }^{14}$. Apesar disso, Israel. país de clima sub-tropical, é um exemplo em que a vacinação oral foi capaz de eliminar quase que totalmente a poliomielite, mediante uma campanha inicial de vacinação em massa, seguida por um excelente programa de imunização de rotina das crianças do primeiro ano de vida ${ }^{21}$.

Entretanto, na maioria dos países de clima tropical e sub-tropical, com serviços de saúde não tão bons quanto o de Israel, programas regionais de vacinação em massa, não seguidos por uma contínua e apropriada imunização dos novos suscetíveis, não conseguiram controlar a doença ou, então, não puderam manter o controle antes alcançado ${ }^{34,49,55,56}$.

Diferentes esquemas de vacinação foram aplicados em diversas áreas do mundo, sempre baseados no princípio fundamental anteriormente mencionado, nas características sócio-econômico-sanitárias e na qualidade do serviço de saúde pública locais. Estes esquemas são: a) somente por campanhas de vacinação em massa; b) por uma campanha inicial de vacinação em massa, seguida apenas por imunização de rotina; c) campanhas periódicas de vacinação em massa e vacinação de rotina; d) somente através da imunização de rotina. Todos estes esquemas permitiram alcançar, com relativa facilidade, o controle e a manutenção da doença, e até mesmo a sua erradicação. nos países de clima predominantemente temperado, onde a estrutura epidemiológica e a qualidade dos serviços de saúde eram eminentemente favoráveis, mas, também, embora com maiores dificuldades. em alguns paises de clima tropical e subtropical (Tabela 1) 1, 5, 12, 19, 21, 24, 31, $36,38,40$.

Adotou-se no município de São Paulo. a partir de 1964, um duplo esquema de vacinação, ou seja. o esquema do item $C$ 
BARBOSA, V. \& STEWIEN, K.E. - Estado imunitário relativo à poliomielite das crianças de 0-12 anos, residentes no município de São Paulo, Brasil e assistidas pelo Hospital Menino Jesus. Rev. Saúde públ., S. Paulo, 9:137-53, 1975.

TABELA 1

Alguns paises das zonas, temperada, tropical e sub-tropical, segundc os esquemas de vacinação oral adotados, em que a poliomielite fol controlada

\begin{tabular}{|c|c|c|}
\hline Esquemas de vacinação & Zonas & Países \\
\hline \multirow{2}{*}{ Campanhas em massa anuais } & Temperada & $\begin{array}{l}\text { Alemanha, Checoslovaquia } \\
\text { (erradicação) e Hungria }\end{array}$ \\
\hline & Tropical e sub-tropical & Espanha \\
\hline \multirow{2}{*}{$\begin{array}{l}\text { Campanha em massa inicial e, } \\
\text { posteriormente, só vacinação de } \\
\text { rotina }\end{array}$} & Temperada & Estados Unidos \\
\hline & Tropical e sub-tropical & $\begin{array}{l}\text { Israel e alguns países da } \\
\text { América do Sul, Africa e } \\
\text { Asia }\end{array}$ \\
\hline \multirow{2}{*}{$\begin{array}{l}\text { Campanhas em massa periódi- } \\
\text { cas e vacinação de rotina, si- } \\
\text { multâneas }\end{array}$} & Temperada & $\begin{array}{l}\text { Ilália (norte), Polônia e } \\
\text { Rússia }\end{array}$ \\
\hline & Tropical e sub-tropical & $\begin{array}{l}\text { Itália (sul) e Rússia (al- } \\
\text { gumas áreas) }\end{array}$ \\
\hline \multirow{2}{*}{ Vacinação de rotina } & Temperada & Inglaterra e Gales \\
\hline & Tropical e sub-tropical & Africa (Uganda) \\
\hline
\end{tabular}

Fonte: Arumanayagam ${ }^{1}$ (1965); Bordete ${ }^{5}$ (1964); Courtois ${ }^{10}$ (1964); Giannelli 19 (1966); Goldblum e col. ${ }^{21}$ (1965); Heyne ${ }^{24}$ (1966); Montefiore e col. ${ }^{3 *}$ (1963); Nehaul ${ }^{36}$ (1964); Pérez Gallardo e col. ${ }^{38}$ (1965); Skovranek ${ }^{48}$ (1964).

da citada tabela. Tal deveu-se à extensão de sua área, ao seu enorme efetivo demográfico acompanhado de intenso crescimento vegetativo, às condiçôes extremamente heterogêneas de suas divisões administrativas, à freqüente chegada, sohretudo na sua periferia, de correntes migratórias do interior do Estado e de outros Estados do Brasil, às características sócio-econômicas de sua população e à estrutura e qualidade de seus serviços de saúde. Essas condições em seu conjunto criaram uma situação em nosso município, em relação a poliomielite, difícil de ser controlada e mantida em sua época atual. Em nossa comunidade, com efeito, podemos verificar pelos dados apresentados na Tabela 2 , coeficientes de morbi- dade por poliomielite paralítica por cem mil habitantes, que em 1967, após 6 anos de vacinação oral, conseguiu-se controlar a doença (Barbosa ${ }^{3}, 1968$ ). Conseguiuse manter esse controle até 1970 e, a partir de 1971, até agora, a incidência da poliomielite vem aumentando, embora com oscilações anuais, sugerindo que, com base nos dados oficiais sobre a sua incidência e sua correlação com o número de doses de vacina anualmente aplicadas. há indicação de que a doença tende a escapar ao controle, voltando aos niveis anteriores a 1967.

$\mathrm{Na}$ maioria dos países e regiões, tanto desenvolvidos como em desenvolvimento. nos quais a vacinação oral foi introduzi- 
BARBOSA, V. \& STEWIEN, K.E. - Estado imunitário relativo à poliomielite das crianşas de 0-12 anos, residentes no municipio de São Paulo, Brasil e assistidas pelo Hospital Menino Jesus. Rev. Saúde públ., S. Paulo, 9:137-53, 1975.

TABELA 2

Morbidade por poliomielite no Municiplo de São Paulo de 1955 a 1973 (coeficientes por 100.000 habltantes)

\begin{tabular}{c|r|r}
\hline Anos & Casos & Coeficientes \\
\hline \hline 1955 & & \\
1956 & 133 & 4,5 \\
1957 & 243 & 7,8 \\
1958 & 316 & 9,5 \\
1959 & 416 & 11,8 \\
1960 & 451 & 12,1 \\
1961 & 794 & 20,0 \\
1962 & 469 & 11,1 \\
1963 & 180 & 4,4 \\
1964 & 517 & 11,9 \\
1965 & 344 & 7,5 \\
1966 & 356 & 7,4 \\
1967 & 223 & 4,3 \\
1968 & 32 & 0,6 \\
1969 & 66 & 1,1 \\
1970 & 66 & 1,1 \\
1971 & 67 & 1,1 \\
1972 & 195 & 3,1 \\
1973 & 114 & 1,8 \\
\hline
\end{tabular}

Fonte: Departamento Regional de Saúde da Grande São Paulo

da, instituiu-se a vigilância epidemiológica da doença, por meio de métodos diretos e indiretos de avaliação. Isto, com o escopo de verificar o comportamento da incidência da virose e relacioná-la ao estado imunitário da população, com vistas a detectar precocemente "bolsōes" de suscetíveis na comunidade, estudar as suas causas e estabelecer programas de vacinação adequados e intensivos, a fim de evitar a recrudescência e novas epidemias de poliomielite ${ }^{11,14,15,23,2 \pi, 29,32,53}$.

Os métodos indiretos baseiam-se: a) no número de casos paralíticos e respectivos coeficientes de morbidade; b) no número de doses aplicadas na população; c) no estado vacinal da criança, por meio de Caderneta de Vacinação. Os métodos diretos, obviamente indispensáveis para uma correta avaliação longitudinal da poliomielite, considerada sob vigilância epidemiológica. são os seguintes: a) inqué- ritos sorológicos periódicos, capazes de medir rigorosamente o estado imunitário da população; b) isolamento e tipagem de poliovírus em doentes e suscetíveis, para evidenciar a sua prevalência e o potencial de transmissão da doença no local; c) marcadores genéticos de vírus (diferenciação intratípica) atualmente de grande valor para determinar a existência ou não de circulação de poliovírus naturais na comunidade.

No caso particular do município de São Paulo os métodos indiretos de avaliação têm sido utilizados até o presente e, dos diretos, apenas o isolamento e a tipagem de poliovírus de casos clínicos, exceto na investigação realizada por Candeias $^{6}$ (1969), que discute, em detalhe, a importância dos marcadores genéticos na vigilância da poliomielite em nosso meio. Em vista do exposto, os autores, preocupados com esta importante lacuna na vigilância da poliomielite entre nós, resolveram realizar o presente inquérito soro-epidemiológico, a fim de alertar as autoridades sanitárias a respeito deste problema e, ao mesmo tempo, fornecerlhes subsídios, que, embora preliminares e restritos à população estudada, permitam um melhor equacionamento da vigilância da poliomielite na Capital de São Paulo.

Objetivou-se, assim, determinar, através da realização do inquérito supramencionado, o estado imunitário relativo à poliomielite, de crianças de 0 a 12 anos de idade, predominantemente pertencentes ao nível sócio-econômico baixo do município de São Paulo, atendidas pelo Hospital Menino Jesus da Prefeitura do município de São Paulo, em relação: a) aos diferentes grupos etários; b) às Zonas "Centro", "Periferia" e "Intermediária": c) ao número de doses de vacina oral recebidas. 

BARBOSA, V. \& STEWIEN, K.E. - Estado imunitário relativo à poliomielite das crianças de 0-12 anos, residentes no município de São Paulo, Brasil e assistidas pelo Hospital Me- nino Jesus, Rev. Saude publ., S. Paulo, 9:137-53, 1975.

\section{MATERIAL E MÉTODOS}

\section{Grupo de Crianças Estudadas}

O grupo em estudo é representado por uma amostra casual de uma população de fácil acesso, constituída de 720 crianças de 0 a 12 anos de idade, sem infecção, residentes no município de São Paulo, predominantemente da classe pobre, que aflui, em qualquer época, ao Hospital Menino Jesus da Prefeitura do município de São Paulo. A coleta de amostras de sangue de cada uma dessas crianças foi feita no mês de julho de 1973.

Essas crianças, conforme pudemos verificar na apuração dos dados, são originárias de todos os distritos e sub-distritos do nosso Município. Com base na classificação desses distritos e sub-distritos. apresentada por Leser e Barbosa ${ }^{30}$, foi feita uma tentativa no sentido de se estudar o estado imunitário das crianças de 0 a 6 anos de idade em relação à poliomielite, em três Zonas, "Central", "Intermediária" e "Periférica", as quais se diferenciam pelo grau de urbanização. condições de saneamento básico e nível sócio-econômico da população.

A composição dessas Zonas é a seguinte: 1) "Central": Aclimação, Barra Funda, Bela Vista, Belenzinho, Bom Retiro. Brás, Cambuci, Cerqueira César, Consolação. Jardim América, Jardim Paulista. Lapa. Liberdade, Moóca, Pari, Perdizes. Pinheiros. Santa Cecília, Santa Ifigência. Sé. Vila Madalena, Vila Mariana; 2) "Intermediária": Alto da Moóca, Casa Verde. Ibirapuera, Indianópolis, Ipiranga. Jabaquara. Limão, Nossa Senhora do ó. Penha. Santana. Santo Amaro, Saúde. Tatuapé. Vila Formosa, Vila Guilherme. Vila Maria, Vila Matilde. Vila Nova Cachoeirinha, Vila Prudente; 3) "Periférica". Brasilândia. Butantan. Cangaiba. Piritulia. Capela do Socorro. Tucuruvi. Vila Jaguara, Ermelino Matarazzo. Guaianazes. Itaquera. Jaguara. Parelheiros. Perul "São Miguel Paulista.
O histórico vacinal das crianças estudadas foi obtido por meio de informações fornecidas pelas crianças ou seus responsáveis e, quando possível, o que ocorreu num pequeno número de vezes, pela Caderneta de Vacinação.

\section{Amostra de Sangue}

As amostras de sangue ( 5 a 6 gotas) foram colhidas mediante a extração digital, em tubos estéreis, e remetidas imediatamente ao laboratório. A fim de se obter, para cada soro, uma diluição aproximada de $1: 10$, adicionava-se quantidade correspondente de meio de Eagle BME, contendo 200 unidades por $\mathrm{ml}$ de penicilina, 200 microgramas por $\mathrm{ml}$ de estreptomicina e 1 micrograma por $\mathrm{ml}$ de anfotericina B (Fungizon, Squibb). Os soros assim diluídos eram separados de seus coágulos por centrifugação a 1.000 r.p.m.. durante $10 \mathrm{~min}$, e mantidos congelados a temperatura de $-20^{\circ} \mathrm{C}$ até serem examinados.

\section{Provas de Neutralização}

As provas de neutralização foram realizadas segundo a microtécnica descrita por Rosenbaum e Sullivan ${ }^{42}$ (1969). As misturas vírus-soro eram incubadas à temperatura ambiente por meia hora e, a seguir, a $4^{\circ} \mathrm{C}$ por $18 \mathrm{~h}$. A suspensão de células Hep-2 era então adicionada, deixando-se as microplacas na estufa contendo atmosfera de $4 \%$ de $\mathrm{CO}_{2}$, durante 48 horas, à temperatura de $37^{\circ} \mathrm{C}$. Após esse período, a leitura dos resultados era realizada ao microscópio invertido Olympus. Um efeito inibidor igual ou superior a $50 \%$ do efeito citopático foi considerado como protetor, indicando presença de anticorpos. Suscetibilidade foi definida como um título de anticorpos menor do que $1: 10$. As estirpes de referência dos três tipos sorológicos foram os protótipos Mahoney. MEF-1 e Saukett. respectivamente. 
BARBOSA, V. \& STEWIEN, K.E. - Estado imunitário relativo à poliomielite das criancas de 0-12 anos, residentes no município de São Paulo. Brasil e assistidas pelo Hospital Menino Jesus. Rev. Saúde públ., S. Paulo, 9:137-53, 1975.

RESULTADOS E DISCUSSAO

\section{Prevalência de Anticorpos e Niveis de Imunidade}

A prevalência de anticorpos para vários grupos etários de $0-12$ anos é apresentada na Figura 1, em termos de porcentagens de crianças suscetíveis, nas quais faltam um, dois ou três tipos de anticorpos neutralizantes contra a poliomielite. Afora o grupo de crianças de 0-3 meses de idade, que reconhecidamente apresentam em maior ou menor grau anticorpos maternos, as crianças triplosuscetiveis (as que não têm nenhum dos três tipos de anticorpos) situam-se predominantemente nos grupos etários de 3 meses a 6 anos (com exceção do grupo de 1-2 anos). Destas crianças são particularmente deficitárias em anticorpos protetores as pertencentes aos grupos de 3-9 e 9-12 meses, atingindo neste último grupo a elevada proporção de $42,5 \%$; no grupo de crianças de 1-2 anos, esta proporção baixou para $13,5 \%$ e no grupo de 3-6 anos foi de $19,5 \%$.

O pico de triplo-suscetíveis no grupo de crianças de 9-12 meses reflete o declínio natural dos anticorpos maternos e a cobertura vacinal quantitativa e qualitativamente deficiente, quanto à imunização básica de 3 doses. Isto se torna ainda mais evidente quando se soma à proporção de triplo-suscetíveis as porcentagens de crianças nas quais faltam um ou dois tipos de anticorpos, acentuando-se o estado de suscetibilidade. Como mostra a Figura 1, entre as crianças de 3-9 meses

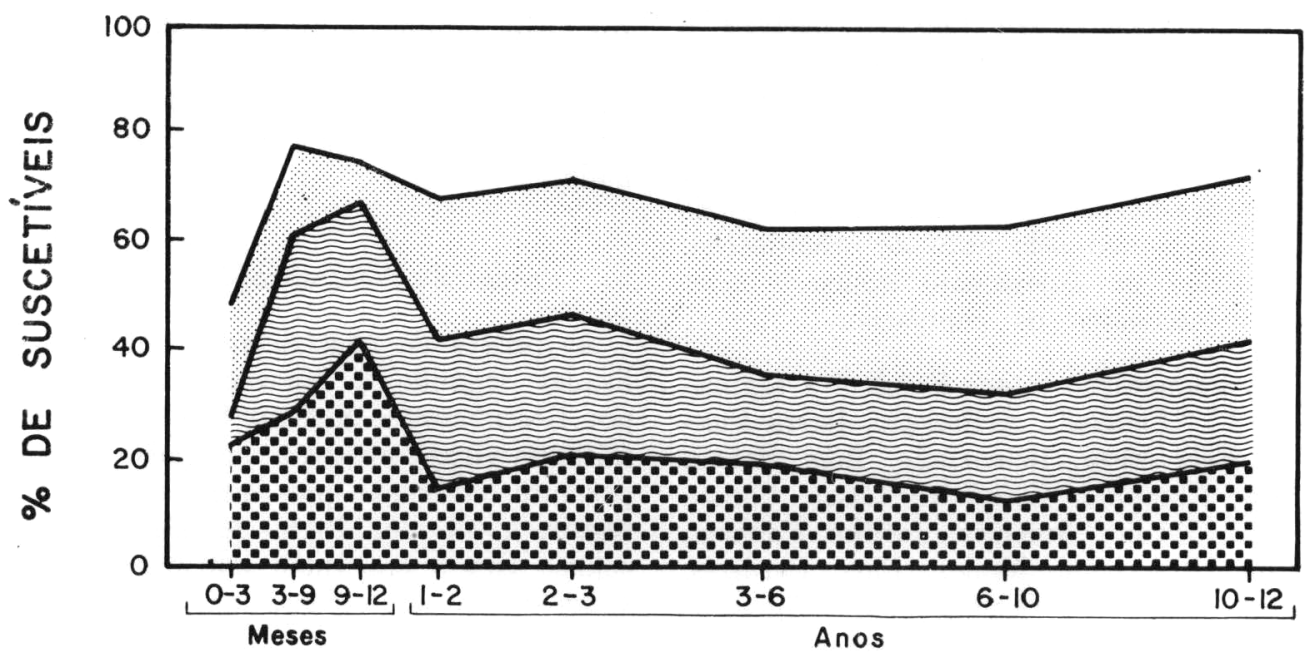

I DADE

LEGENDA:

$\%$ de mono-suscetiveis
(ausência de I tipo de anticorpos)
$\%$ de duplo-suscetiveis
(ausência de 2 tipos de anticorpos)
\% de triplo-suscetiveis
(ausência de 3 tipos de anticorpos)

Fig. 1 - Suscetibilidade a um ou mais tipos de poliovirus, segundo os grupos etários, das crianças assistidas pelo Hospital Menino Jesus da Prefeitura do Municipio de São Paulo - Julho, 1973. 
BARBOSA, V. \& STEWIEN, K.E. - Estado imunitário relativo à poliomielite das crianças de 0-12 anos, residentes no município de São Paulo, Brasil ? assistidas pelo Hospital Menino Jesus. Rev. Saude puibl., S. Paulo, 9:137-53, 1975.

de idade $78,4 \%$ são suscetíveis a pelo menos um dos três tipos de vírus da poliomielite; entre as crianças de 9-12 meses de idade esta proporção foi praticamente a mesma $(75 \%)$; entre as crianças maiores, mais de $60 \%$ são parcialmente suscetíveis; e, finalmente, verificou-se uma tendência de aumento no grupo etário de 10-12 anos, passando para $71,6 \%$.

Num programa de vigilância longitudinal da poliomielite em Houston, Texas, área de clima sub-tropical, Melnick e col. ${ }^{33}$ verificaram no primeiro de dois inquéritos sorológicos, realizado imediatamente após a campanha inicial de vacinação oral em massa, realizada em 1963, que a proporção de triplo-negativos era quase inexistente, exceção feita a um pequeno pico no grupo de 3-9 meses $(10 \%)$, sendo, por outro lado, a porcentagem de triplo-imunes acima de $90 \%$ em todos os grupos vacinados de crianças pertencentes predominantemente ao nível sócioeconômico baixo. No inquérito de 1968, 5 anos após a campanha de vacinação oral em massa, período durante o qual somente se vacinou nas clínicas oficiais de atendimento público, quando procuradas pelos pais para vacinar os seus filhos, aumentou a proporção de triplo-suscetíveis, especialmente no grupo de 3-9 meses, para nada menos do que $62 \%$.

Isto indica que: a) quando a vacinação em massa é adequadamente administrada, pode-se alcançar, mesmo em áreas de clima sub-tropical, excelentes resultados na prevenção contra a poliomielite; b) quando não se mantém a vacinação, após a campanha inicial, de modo contínuo e eficiente, ocorre a formação de sensíveis lacunas de imunidade, dando margem ao reaparecimento da temível doença, fato que sucedeu em Houston em 1968. E de se notar que a população do presente estudo apresenta semelhante lacuna de imunidade à de Houston em 1968, com todas as suas conseqüências óbvias. apesar dos contínuos esforços rea- lizados pelas nossas autoridades sanitárias na manutenção da vacinação em São Paulo.

\section{Prevalência de anticorpos por sorotipo}

A Figura 2 apresenta, em contraste com a Figura 1, que trata da suscetibilidade, a percentagem de crianças positivas (imunes) para cada sorotipo de poliovírus (diluição $1: 10$ ). Observa-se uma proporção de crianças com anticorpos para os 3 sorotipos abaixo de $50 \%$, na idade de 0-3 meses, e sua subseqüente elevação na idade de 3-6 meses. Isto parece refletir os primeiros efeitos da vacinação oral básica nesta idade, o que é reforçado pela elevação subseqüente, no grupo etário seguinte de 6-9 meses, dos anticorpos contra os poliovirus dos tipos 1 e 2, aumentando os anticorpos do tipo 3 , a seguir, no grupo de 9-12 meses.

No grupo de 0-3 meses de idade, a linha pontilhada mostra a presença de anticorpos dos 3 tipos na diluição de $1: 5$, nas percentagens acima de $70 \%$ para os tipos 1 e 2 e de $60 \%$ para o tipo 3 , que são significativamente maiores do que aquelas verificadas na diluição de $1: 10$. mostrando que anticorpos maternos para os 3 sorotipos estão presentes na maioria das crianças nesta idade, se bem que em níveis baixos. 0 mesmo fato foi observado recentemente por Bastos e col. ${ }^{4} \mathrm{em}$ 3 cidades do Espírito Santo e por Neves e col. ${ }^{3 \tau}$ em São Paulo.

Em Houston, a menor proporção de imunes, para cada sorotipo, encontrada por Melnick e col. ${ }^{33}$, em 1968, foi entre as crianças do primeiro ano de vida, sendo particularmente acentuada nos grupos etários de 3-6 e 6-9 meses para os tipos 1 e 2 e para os grupos de 3-6 e 9-12 meses para o tipo 3 , caindo as percentagens, respectivamente, para apenas, $20 \%$ e a $10 \%$. A Figura 2 revela uma situação semelhante, com a maior lacuna 
BARBOSA, V. \& STEWIEN, K.E. - Estado imunitário relativo à poliomielite das crianças de 0-12 anos, residentes no municipio de São Paulo, Brasil e assistidas pelo Hospital Menino Jesus. Rev. Saúde públ., S. Paulo, 9:137-53, 1975.

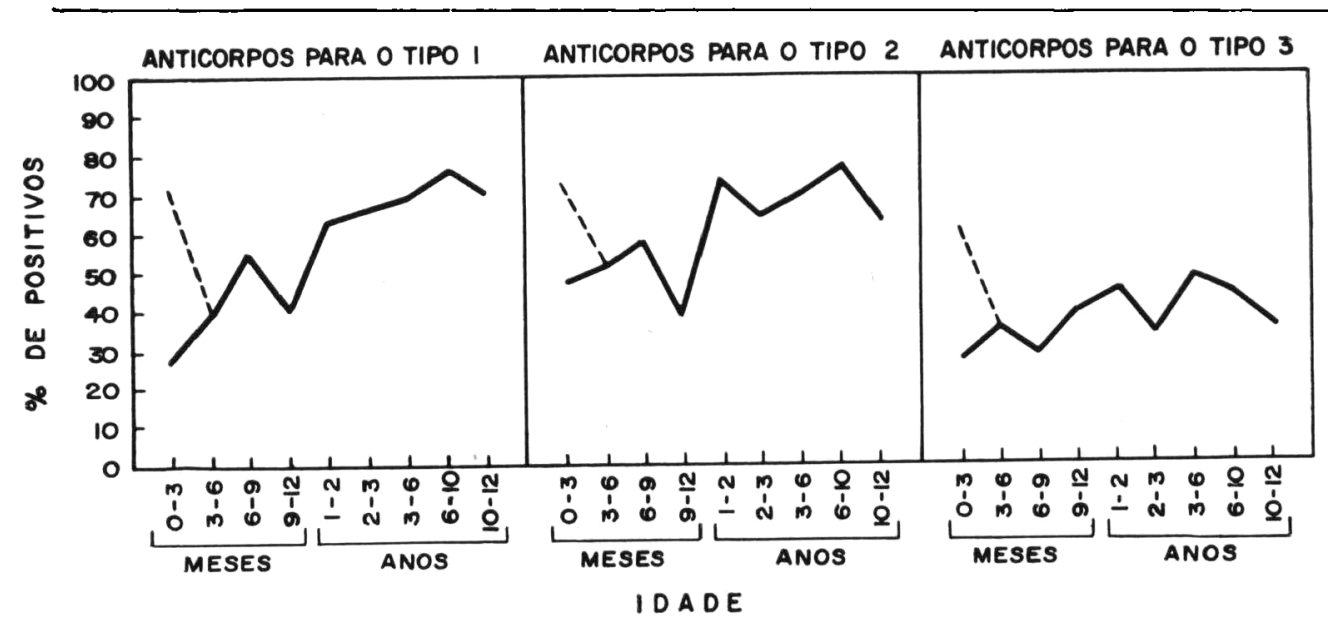

\section{LEGENDA :}

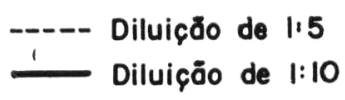

Fig. 2 - Prevalência de anticorpos para os poliovirus dos tipos 1, 2 e 3 , segundo os grupos etários das crianças assistidas pelo Hospital Menino Jesus da Prefeitura do Município de São Paulo - Julho, 1973.

entre as crianças do primeiro ano de vida, embora as percentagens de positividade não fossem tão baixas, sendo os menores valores em torno de $40 \%$ (3-6 meses). $37 \%$ (9-12 meses) e $27 \%$ (6-9 meses) para os tipos 1,2 e 3 , respectivamente. Isto sugere que, embora a situação do estado imunitário da população estudada seja melhor para os 3 sorotipos do que a de Houston em 1968, provavelmente devido à vacinação em massa e de rotina realizada em São Paulo desde 1962, a mesma ainda não atingiu o nível mínimo desejável, que seria em torno de $80 \%$ para manter a doença soh rontrole.

A Tabela 3 mostra que. em 1973, o maior número de casos de poliomielite ocorreu entre as crianças do primeiro ano de vida. atingindo uma percentagem de $43 \%$. sendo para os grupos $1-2$ e $2-3$ anos. respectivamente. de $35 \%$ e $15 \%$.

As precárias taxas de positividade para o sorotipo 3, observadas em nosso estudo. lambém foram encontradas em outro: estudos em diversas partes do mundo 20,25 , $32,33,47$. Esce fenômeno decorre, de um lado, do poder imunogênico menor da estirpe vacinal correspondente (Leon 12

T A B E L A 3

Casos de poliomielite, segundo a idade, no Município de São Paulo em 1973 (percentagem)

\begin{tabular}{c|cc}
$\begin{array}{c}\text { Idade } \\
\text { em anos) }\end{array}$ & Casos & $\%$ \\
\hline-1 & 48 & 42,0 \\
1 & 38 & 33,3 \\
2 & 14 & 12,3 \\
3 & 5 & 4,4 \\
4 & 3 & 2.6 \\
5 & 2 & 1.8 \\
6 & 2 & 1.4 \\
7 & - & - \\
8 & 1 & 0,9 \\
15 e + & 1 & 0,9 \\
\hline Total & 114 & 100,0 \\
\hline
\end{tabular}

Fonte: Departamento Regional de Saúde da Grande São Paulo 
BARBOSA, V. \& STEWIEN, K.E. - Estado imunitário relativo à poliomielite das crianças de 0-12 anos, residentes no municipio de São Paulo, Brasil e assistidas pelo Hospital Menino Jesus. Rev. Saúde públ., S. Paulo, 9:137-53, 1975.

$\left.a_{1} b\right)$, como pôde ser verificado em algumas investigações bem conduzidas ${ }^{32,47,30}$, e, de outro lado, da menor capacidade dos anticorpos, para este tipo, de neutralizar estirpes heterólogas, como foi observado com o protótipo Saukett ${ }^{25}$. A solução do problema talvez deva girar em torno das seguintes opções: a) utilizar, nas revacinações, vacina oral que apresente uma proporção relativa maior para a estirpe do tipo 3 ; b) empregar vacina oral que contenha estirpe atenuada do tipo 3 mais imunogênica, o que já vem sendo estudado em algumas partes do mundo.

\section{Niveis de imunidade e vacinação oral}

É fato conhecido que em zonas de clima temperado a vacinação oral adequada determina com relativa facilidade, taxas de soroconversão maiores do que $90 \%$ dos indivíduos vacinados, independentemente do esquema de imunização adota-

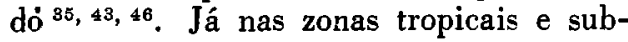
tropicais esta situação, desejável, se mostrou mais difícil de ser obtida, em parte devido à intensa circulação de enterovírus durante quase todo ano ${ }^{7,8,39}$, interferindo com os vírus da vacina oral, baixando as taxas de soroconversão para apenas $70 \%$ ou até menos, como mostraram estudos conduzidos em nosso meio ${ }^{4}$.

As excelentes taxas de soroconversão inicialmente alcançadas $(90 \%$ ou mais de triplo-positivos) por Moura ${ }^{35}$, em Santo André (São Paulo), em condições excepcionalmente favoráveis quanto à qualidade, conservação e aplicação da vacina. no estudo piloto da vacinação oral (Sahin) entre nós, em 1961 (com o intu:to de fornecer subsídios seguros para a introdução da vacina oral na cidade de São Paulo), não puderam mais ser verificados em nosso pais em estudos posteriores. Para citar um deles, o do Espírito Santo apresentou taxas de soroconversão de $80 \%$ para os tipos $1+2+$ de apenas
$60 \%$ para o tipo 3 , após a administração de 3 doses a cerca de 600 crianças estudadas em 3 localidades diferentes ${ }^{4}$.

Isto nos faz perguntar: Que níveis de imunidade para a poliomielite deveriam ser esperados em nossa população caso tivesse recebido a mesma cobertura vacinal desses estudos? Em resposta, tudo indica que, na melhor das hipóteses, resultados semelhantes aos encontrados por Moura ${ }^{35}$, em Santo André e, possivelmente, no pior dos casos, resultados semelhantes aos encontrados no Estado do Espírito Santo.

Os dados da Tabela 4, que mostram os níveis de imunidade das crianças de 0-12 anos do nosso estudo, de acordo com o número de doses recebidas, indicam o seguinte: a) o grupo etário de 0-5 anos, mais suscetível à poliomielite, apresenta, apenas, cerca de $60 \%$ de crianças duplo mais triplo-positivas, entre as que receberam 3 ou mais doses de vacina oral trivalente; b) no mesmo grupo, a proporção de triplo-negativos, entre as crianças que receberam 3 ou mais doses de vacina, é de $17,1 \%$; c) no grupo etário de 5-10 anos, o contingente de crianças duplo mais triplo-imunes, que receberam 3 ou mais doses de vacina, não ultrapassa os $66,4 \%$; d) no grupo etário de $10-12$ anos, a proporção de duplo mais triploimunes com 3 ou mais doses de vacina é, para nossa surpresá, menor do que no grupo anterior de 5-10 anos, mostrando apenas $61,7 \%$.

Comparando estes resultados com os dos estudos anteriormente citados, é de se notar que os níveis de imunidade da população em estudo, no que concerne ao grupo etário de 0-5 anos, o mais exposto à doença em nosso meio, são muito inferiores aos de Moura ${ }^{3 i} \mathrm{e}$, também, inferiores aos do Espírito Santo. Na Figura 3 , apresentamos a incidência da poliomielite na Capital de São Paulo e sua relação rom o número total de doses de vacina oral aplicadas a partir de 1962 até 1973. 
BARBOSA, V. \& STEWIEN, K.E. - Estado Imunitário relativo à poliomielite das crianças de 0-12 anos, residentes no município de São Paulo, Brasil e assistidas pelo Hospital Menino Jesus. Rev. Saúde públ., S. Paulo, 9:137-53, 1975.

Pode-se notar que de 1967 a 1969, anos em que mais se vacinou, houve uma sensível queda na incidência da poliomielite, atingindo o coeficiente de morbidade valores em torno de $1: 100.000$ habitantes. Quando em 1970 diminuiu o número de doses de vacinas aplicadas, houve nítida elevação do número de casos clínicos no ano seguinte. Intensificou-se novamente a vacinação em 1971, ocorrendo conseqüentemente queda do número de casos no ano de 1972. Voltando a diminuir a intensidade de vacinação neste ano (e em 1973), foi registrado novo aumento do número de casos em 1973, acusando o coeficiente um valor de
3:100.000. Se não houver uma intensificação na vacinação anti-poliomielítica, é de se esperar uma volta aos niveis de incidência de 1966 ou mesmo aos dos anos anteriores. $\mathbf{E}$ de se notar, por outro lado, que de 1967 a 1973 o grupo de crianças de 0-5 anos de idade recebeu, em média, em torno de $80 \%$ do total de doses aplicadas em cada ano.

Isto posto, como explicar os baixos níveis de imunidade verificados em nosso inquérito?

Partindo do pressuposto de que é elevado o número de doses de vacina anual-

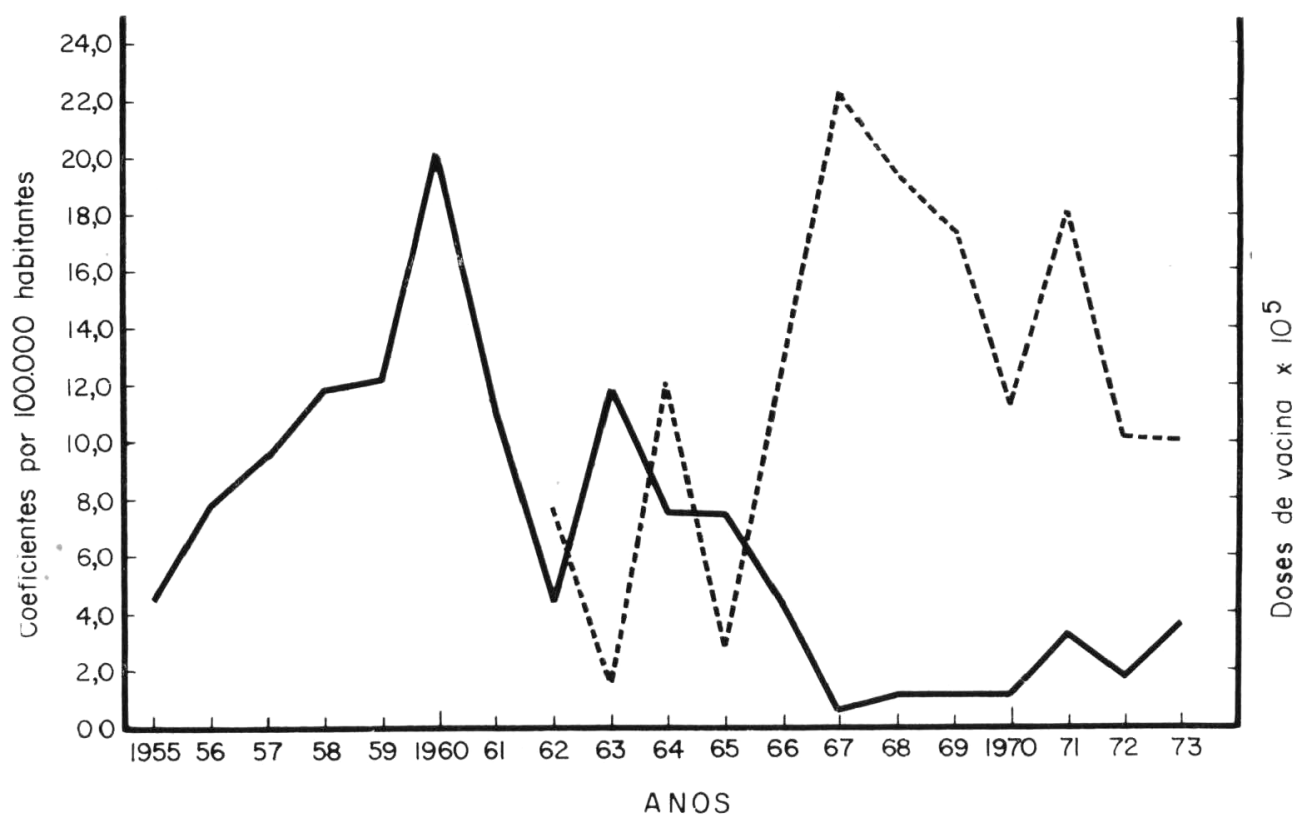

LEGENDA:

- Morbidade por Poliomielite

...-- Número de doses de vacina

FONTE : Departamento Regional de Saúde da Grande Säo Paulc

Fig. 3 - Morbidade por pollomielite e número de doses de vacina oral trivalente de Sabin no município de São Paulo - 1955 a 1973. 


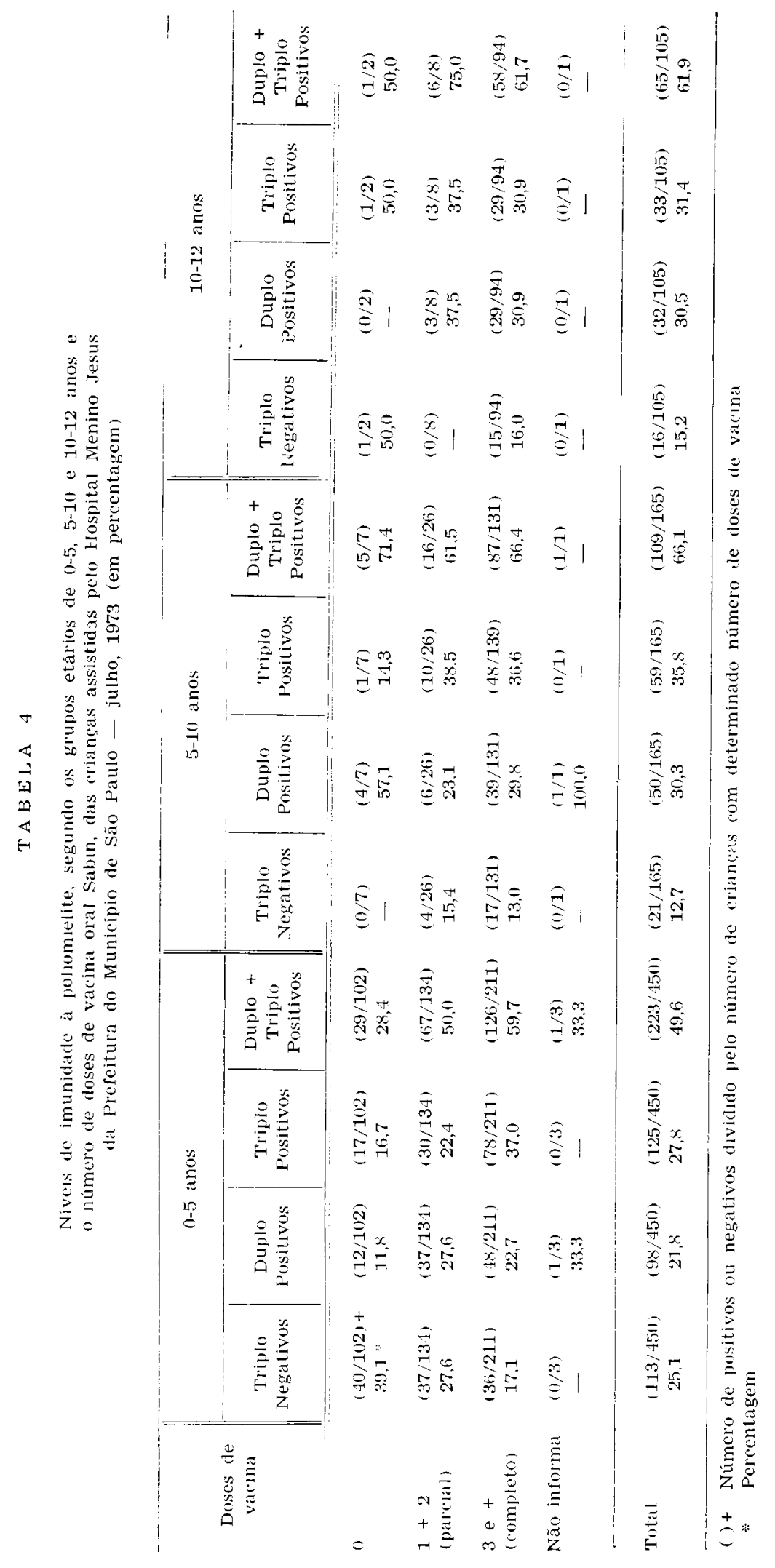


BARBOSA, V. \& STEWIEN, K.E. - Estado imunitário relativo à poliomielite das crianças de 0-12 anos, resiaentes no municipio de São Paulo, Brasil e assistidas pelo Hospital Menino Jesus. Rev. Saúde públ., S. Paulo, 9:137-53, 1975.

mente administradas, embora, a nosso ver, ainda insuficiente, a resposta, talvez, seria que, além do fenômeno da interferência de enterovírus, que circulam em nosso meio durante todo o ano ${ }^{7,8}$, devem influir fatores de ordem administrativa $e$ operacional. E preciso ter em vista, também, a complexidade da estrutura epidemiológica do município de São Paulo, para a poliomielite, onde o enorme número de sua população, vivendo em elevada densidade demográfica, a contínua migração de crianças não vacinadas provenientes de outras áreas com alta prevalência de poliovírus e a vacinação insuficiente dos novos suscetíveis são, também, outros fátores que favorecem a contínua ocorrência de casos de poliomielite ${ }^{2}$. Tudo leva a crer, então, que devido a todos estes fatores e ao baixo estado imunitário relativo à doença, a poliomielite "continua a ser, atualmente, um grave problema de Saúde Pública em potencial entre nós, a demandar acentuada intensificação e melhoria da vacinação oral. Esta impressão é, sem dúvida, reforçada pela elevada proporção de crianças triplo-negati- vas $(17,1 \%)$ no grupo etário de $0-5$ anos, referida no item 2 , quando esta percentagem deveria ser mínima $(1-2 \%)$ ou ausente ${ }^{20}$.

No grupo de 5-10 anos deveríamos esperar um nível de imunidade de pelo menos $80 \%$ de duplo mais triplo-positivos, a exemplo de Houston e, entretanto, verificamos apenas $66,4 \%$. No grupo etário de 10-12 anos, notamos uma diminuição do nivel de imunidade (Tabela 3 e Figuras 1 e 2), apresentando a proporção de $61,7 \%$ de duplo mais triplo-imunes. Fenômeno semelhante foi verificado em Houston, por Melnick e col. ${ }^{33}$, em 1968. Alguns estudos longitudinais bem controlados demonstraram o declínio progressivo nos níveis de anticorpos protetores, com o tempo, principalmente para o tipo 3. A queda nos níveis de anticorpos é explicada por Chumakov e Voroshilava ${ }^{9}$ e Cox ${ }^{13}$, principalmente, pelo declínio quase total da imunização latente nas comunidades vacinadas e pela variável capacidade reacional dos indivíduos. No caso específico de São Paulo, a enorme

TABELA 5

Niveis de imunidade à poliomielite, segundo as Zonas "Central", "Intermediária" e "Periférica", do Município de São Paulo, no grupo etário de 0-6 anos, das crianças assistidas pelo Hospital Menino Jesus da Prefeitura do Município de São Paulo, julho, 1973

\begin{tabular}{|c|c|c|c|}
\hline Zonas & Duplo Positivos & Triplo Positivos & $\begin{array}{c}\text { Duplo }+ \text { Triplo } \\
\text { Positivos }\end{array}$ \\
\hline Central & $\begin{array}{l}(20 / 89)+ \\
22,5 *\end{array}$ & $\begin{array}{l}(24 / 89) \\
27,0\end{array}$ & $\begin{array}{c}(44 / 89) \\
49,4\end{array}$ \\
\hline Intermediária & $\begin{array}{l}(60) / 286) \\
21,0)\end{array}$ & $\begin{array}{l}(85 / 286) \\
29,7\end{array}$ & $\begin{array}{l}(145 / 286) \\
50,7\end{array}$ \\
\hline Periféricat & $\begin{array}{l}(27 / 117) \\
23,1\end{array}$ & $\begin{array}{l}(32 / 117) \\
27,4\end{array}$ & $\begin{array}{l}(59 / 117) \\
50,4\end{array}$ \\
\hline
\end{tabular}

( ) + Número de positivos divididos peio número de criancas de determinada zona

* Percentagem 
BARBOSA, V. \& STEWIEN, K.E. - Estado imunitário relativo à poliomielite das crianças de 0-12 anos, iesidentes no municíplo de São Paulo, Brasil e assistidas pelo Hospital Menino Jesus. Rev. Saride puibl., S. Paulo, 9:137-53, 1975.

aglomeração populacional de complexa situação sócio-econômico-sanitária, provavelmente reforça a expressão destes dois fatores. Urge, pois, a necessidade de realizar novos inquéritos para verificar melhor a extensão deste fenômeno. A fim de impedir a formação de lacunas no estado imunitário dos grupos etários maiores, já vem sendo realizada na União Soviética, desde 1966, a revacinação periódica de todas as crianças em idade escolar, sendo aplicada a $10^{2}$ dose de vacina oral trivalente, quando a criança ingressa na escola, e a $2 .^{a}$ dose, num dos dois últimos anos do $1 .^{\circ}$ grau $^{9}$.

\section{Niveis de imunidade e área geográfica}

A Tabela 5 apresenta os resultados do inquérito em termos de crianças duplo mais triplo-imunes do grupo etário de 0-6 anos. Pode-se notar que, paradoxalmente, nas três áreas geográficas da $\mathrm{Ca}$ pital, como foram definidas na seção de material e métodos, o estado imunitário é o mesmo, merecendo, pois, todas, no que tange à vacinação de sua população suscetível à doença, a mesma atenção por parte das autoridades sanitárias locais.

\section{CONCLUSOES}

1. Os haixos níveis de imunidade observados na população infantil estudada, principalmente nos grupos etários de $0-5$ anos, atingindo um pico de triplo-suscetíveis de $42,5 \%$ no grupo etário de 9-12 meses e havendo uma proporção enorme de $75 \%$ de crianças suscetíveis a pelo menos um dos 3 tipos de poliovírus, pa- recem indicar que, pelo menos para a população estudada, a vacinação de manutenção, apesar dos esforços de nossas autoridades sanitárias, não vem alcançando os seus objetivos nos últimos anos, como mostra o crescente número de casos de poliomielite ocorridos na Capital.

2. A baixa percentagem de anticorpos do tipo $3 \mathrm{em}$ praticamente todos os grupos etários de 0-12 anos, fenômeno também observado em outras partes do mundo, indica a necessidade de se levar em consideração este problema nos programas de vacinação.

3. A proporção insuficiente de duplo mais triplo-imunes entre as crianças de 0-5 anos, que recereberam 3 ou mais doses de vacina oral, mostra que uma criança vacinada não está necessariamente imune, pela influência de diversos fatores inerentes às áreas de clima tropical $\mathrm{e}$ sub-tropical, que são agravados em lugares que apresentam complexa situação sócio-econômico-sanitária, como é o caso da Capital de São Paulo, com uma população de mais de 8 milhões de habitantes.

4. Em face às conclusões dos três itens anteriores, torna-se necessário intensificar a vacinação oral no município de São Paulo, em todos os seus distritos e subdistritos, não poupando esforços no sentido de melhorar a qualidade da vacinação, bem como aperfeiçoar os programas de vigilância da poliomielite, realizando periodicamente inquéritos soro-epidemiológicos.

5. Estes inquéritos hoje se fazem necessários para detectar a formação de lacunas de imunidade nos diferentes segmentos e classes sociais da população, devendo-se dirigir, preferivelmente, para os grupos etários de 0-15 anos. 
BARBOSA, V. \& STEWIEN, K.E. - Estado imunitário relativo à poliomielite das crianças de 0-12 anos, residentes no município de São Paulo, Brasil e assistidas pelo Hospital Menino Jesus. Rev. Saúde públ., S. Paulo, 9:137-53, 1975.

\section{RSPU-B $/ 255$}

Barbosa, V. \& STEWIEN, K.E. - [Immunity status to poliomyelitis of 0-12 years old children living in S. Paulo city, Brazil and using the Menino Jesus Hospital]. Rev. Saúde públ., S. Paulo, 9:137-53, 1975.

SUMMARY: The prevalence of neutralizing antibodies for the three types of polioviruses and the immunity levels of different age groups were determined through a seroepidemiological survey, in a population of 0 to 12 year old children, living in the city of S. Paulo and attending the Menino Jesus Hospital. The results showed a high number of children susceptible to infection by polioviruses, mainly in the 9-12 month age bracket where the proportion of individuals completeley susceptible was 42.5\%. In this group the prevalence of type 1, 2 and 3 antibodies was only about 40\%. For the 0-5 year old children only $60 \%$ were found to be double plus triple immune, among those who got three or more doses of oral trivalent vaccine. The results also showed that the immunity status of the children in this group was the same in the three geographical zones of city of S. Paulo, there being abount $50 \%$ of double plus triple immune children. These results show low levels of immunity mainly for those in the first year of life. These is then a clear necessity for new serological surveys, besides intensification and improving of routine vaccination against poliomyelitis in our region.

UnIterms: Poliomyelitis. Immunity. Epidemiologic survey, S. Paulo, Brazil. Poliovirus.

\section{REFERENCIAS BIBLIOGRAFICAS}

1. ARUMANAYAGAM, P. - Mass Imunization against Poliomyelitis in Ceylon in 1962 Using Sabin Oral Vaccine. J. trop. Med. Hyg., 68:105-9, 1965.

2. BARBOSA, V. - Contribuição para o conhecimento da epidemiologia da poliomielite no municipio de São Paulo. São Paulo, 1963. [Tese de Doutoramento - Faculdade de $\mathrm{Hi}$ giene e Saúde Pública da USP]

3. BARBosA, V. - Estado atual do problema da poliomielite no municipio đe São Paulo. Rev. Saúde públ. S. Paulo, 2:68-80, 1968.

4. BASTOS, N.C. de B. et al. - Programa antipoliomielítico en el Brasil: Estudio de niveles de immunidad. Bol. Ofic. sanit. panamer, 75:511-22, 1973.

5. BORDETE, P. - La vaccination contre la poliomyélite en Belgique. Brux. med., 44:907-11, 1964.

6. CANDEIAS, J.A.N. - Isolamento $e$ identificação intratipica de cêpas de poliovirus associadas com a admi. nistraça da vacina Sabin. São Pau-
10, 1969. [Tese - Faculdade de Higlene e Saúde Pública da USP]

7. CARVAlHo, R.P. de S. - Contribuição para o estudo dos enterovirus. São Paulo, 1965. p. 52-6. [Tese de Livre-Docência - Faculdade de $\mathrm{Me}$ dicina da USP]

8. CHRIstovão, D. de A. et al, - Condiçōes sanitárias das águas de irrigação de hortas do município de São Paulo, II. Isolamento de vírus entéricos. Rev. Saúde públ., S. Paulo, 1:12-7, 1967 .

9. CHUMAKOV, M.P. \& VOROSHILAVA, M.K. - The present status of poliomyelitis immunization in the USSR. Washington, D.C., Pan American Health Organization, 1967. $\mathrm{p}$ 190-7. (Scient. publ., 147)

10. CLARKE, S.K.R. et al. - A smallscale trial of type III attenuated living poliovirus vaccine. Brit. med.

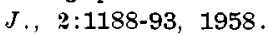

11. COCKBURN, W.C. \& DROZDOV, S.G. - Poliomyelitis in the world. Bull. Wld. Hlth. Org., 42:405-17, 1970. 
BARBOSA, V, \& STEWIEN, K.E. - Estado ımunitárıo relativo à polıomılıte das crianças de 0-12 anos, residentes no município de São Paulo, Brasil e assistıdas pelo Hospital Menino Jesus. Rev. Saúde públ., S. Paulo, 9:137-53, 1975.

12. COURTOIS, G. \& DE WEVER, A. Compagne de vaccination de masse par le poliovirus vivant attenué et problèmes posés par sa réalisation. Brux. med., 44:415-26, 1964.

13. COX. H.R. - Duration of immunity following live poltovirus vaccine. Washington, D.C., Pan American Health Organization, 1967. p. 17984. (Scient. publ., 147)

14. DROZDOV, S.G. \& COCKBLRN, W.C. - The state of poliomyelitis in the world. In: INTERNATIONAL CONFERENCE ON VACCINES AGAINST VIRAL AND RICKETTSIAL DISEASES OF MAN, $1^{\text {st }}$ Washington, D.C., 1966. Washington, D.C., Pan American Health Organization, 1967. $\mathrm{p}$ 198-209. (Sclent. publ., 147)

15. DROZDOV, S.C. \& COCKBURN, W.C. - Poliomyelitis in the developed and developing contries. In: INTER. NATIONAL CONFERENCE ON THE APPLICATION OF VACCINES AGAINST VIRAL, RICKETTSIAL, AND BACTERIAL DISEASES OF MAN. Washington, D.C., 1970. Washington, D.C., Pan American Health Organization, 1971. p 16370. (Scient. publ., 226).

16. FELDMAN; R.A. et al. - Oral poliovirus vaccination in children: A study suggesting enterovirus interference. Pediatrics, 33:526-33, 1964.

17. GELFAND, H.M. et al. - Intrafamilial and interfamilial spread of living vaccine strains of polioviruses. $J$ Amer, med. Ass., 170:2039-48, 1959.

18. GELFAND, H.M. et al. - The spread of living attenuated strains of polioviruses in two communities in Southern Louisiana. Amer. J. publ. Hlth., 50:767-78. 1960 .

19. GIANNELLI, G. - Appunte sulle campagne anti-poliomielitiche, 1964-1966. Notiziario dell'Amministrazione San!taria, 19:235-55, 1966

20. GOLD, E, et al - Immune status of children one to four years of age as determined by history and antibody measurement. Neu. Engl. J. Med., $289: 231-5,1973$.

21. GOLDBLLM. $N$. et al. - Poliomyelitis in Israel, 1949 to 1963, and the Re- cent Lse of attenuated Poliomyelitis Vaccine in its Control. Israel $J$ med. Sci., 1:235-42, 1965.

22. HALE, J.H. et al - Large-scale use of Sahin Type 2 attenuated poliovirus vaccine in Singapore during a type 1 poliomyelitis epıdemic Brit. med. J., 1:1541-9, 1959.

23. HENNEBERG, G. - Probleme der Schluckimpfung gegen poliomyelitis. Minch. med. Wschr., 111:1701-7. 1969 .

24. HEYNE, D. - Poliomyélite en Belg1que. In: SYMPOSIUM OF THE EUROPEAN ASSOCIATION AGAINST POLIOMYELITIS AND ALLIED DISEASES, $11^{\text {th }}$, Rome, 1966. Proceedings, Rome, 1966.

25. HOHER, P.G. et al. - Beurtellungskriterien ( $r$-Wert der Immunisierungsdynamik, kumulative Impfbetelligung, Index der relativen Impfbeteiligung) fur die Uberwachung der Poliomyelitis in einer Grosstadt des Ruhrgebiets. Zbl. Bakt. Hyg., I. Abt Orig.: 156:471-85, 1973.

26. HORSTMANN, D.M. et al. - Attenuated typa 1 poliovirus vaccine: its capacity in infect and to spread from "Vacciness" Within Institutional Population. J. Amer. med. Ass. $170: 1-8,1959$.

27. HORSTMANN, D.M. et al. - Trial use of Sabun's attenuated type 1 poliovirus vaccine in Village in Sothern Arizona. Amer. J. Hyg., 70:169-84. 1959 .

28. LEE, L.H. et aI, - Prevention of poliomyelitis in Singapore by live vaccine. Brit. med. J., 1:1077-80, 1964

29. LENNARTZ, H. \& FISCHER, K. Uberwachung der Poliomyelitis-Verbreitung in Hamburg. Arch. Hyg Berl.. 151:757, 1967.

30. LESER, W. \& BARBOSA, V. - Relacionamento de certas caracteristicas populacionais com a mortalidade infantil no municipio de São Paulo. de 1950 a 1970. Probl. bras., 10 (109): 17-33, 1972 .

31. MANCINI, G. et al - Vaccination against Poliomyelitis in Italy. I. The Epidemiological Situation and 
BARBOSA, V. \& STEWIEN, K.E. - Estado imunitário relativo à poliomielite das crianças de 0-12 anos, residentes no município de São Paulo, Brasil e assistidas pelo Hospital Menino Jesus. Rev. Saúde públ., S. Paulo, 9:137-53, 1975.

the Organization of Vaccination Programs with Inactivated and Live Virus Vaccines. Ann. Sclavo, 7:518. 1965.

32. MELNICK, J.L. - Poliomyelitis Vaccine: present status, suggested use, desiraible developments. In: INTERNATIONAL CONFERENCE ON THE APPLICATION OF VACCINES AGAINST VIRAL, RICKETTSIAL, AND BACTERIAL DISEASES OF MAN. Washington, D.C., 1970 Washington, D.C., Pan American Health Organization, 1971. p. 17181. (Scient. publ., 226).

33. MELNICK, J.L. et al. - Developing gap in immunity to poliomyelitis in an Urban Area. J. Amer. med. Ass., 209:1181-5, 1969.

34. MONTEFIORE, D. et al. - Trial of type 1 oral poliomyelitis vaccine (Sabin) in Nigerian Children. Brit. med. J., 1:1569-72, 1963.

35. MOURA, R.A. de A. - Resultados de uma campanha de vacinação $\mathrm{em}$ massa contra a poliomielite em co. munidade do Estado de São Paulo: importancia do levantamento soro. lógico. São Paulo, 1970. p. 116. [Tese-Doutoramento - apresentada à Faculdade de Ciências Farmacêutícas da USPJ

36. NEHAUL, B.B.G. - Immunization Against Poliomyelitis During the Epidemic in British Guiana 19621963. J. trop. Med, Hyg., 67:297-9, 1964.

37. NEVES, W.E. et al. - Vacinação antipoliomielitica, tipo Sabin, em criancas com um e três meses de idade. Rev. Inst. Med. trop. S. Paulo, 10: 376-82, 1968.

38. PEREZ GALlARDO, F. et al. - Resultados de la Campaña Nacional de Vacinación Antipoliomielítica por Via Oral en España - Estudio Virologico y Epidemiológico. Rev. Sanid. Hig. publ., Madrid, 39:537-61, 1965.

39. RAMOS ALVAREZ, M. - Poliomyelitis. In: INTERNATIONAL CONFERENCE ON VACCINES AGAINST VIRAL AND RICKETTSIAL DISEASES OF MAN, 1.t. Washington, D.C., 1966. Washington. D.C.. Pan American
Health Organization, 1967. p. 2134. (Scient. publ., 147).

40. RAmos alvarEz, M. et al, - Use of Sabin's live poliovirus vaccine in Mexico: results of a large scale trial, in live poliovirus vaccines. In: INTERNATIONAL CONFERENCE ON LIVE POLIOVIRUS VACCINE. $2^{\text {ndt, }}$ Washington, D.C., 1960. Papers presented. Washington, D.C., Pan American Health Organization, 1960、 p. 368-409. (Scient. publ., 50).

41. RAMOS ALVAREZ, M, et al. - Viral and serological Studies in Children Immunized with live Poliovirus vaccine: Preliminary Report of a Large Trial Conducted in Mexico. In: INTERNATIONAL CONFERENCE ON LIVE POLIOVIRUS VACCINES, $1^{\mathrm{st}}$, Washington, D.C., 1959. Papers presented. Washington, D.C., Pan American Sanitary Bureau, 1959. p. 483-94. (Scient. publ., 44).

42. ROSENBAUM, M.J. \& SULLIVAN, E.J. - In: AMERICAN PUBLIC HEALTH ASSOCIATION. Diagnostic procedures for viral and rickettsial diseases: $4^{\text {th }}$ ed. New York, 1969. p. 125-6.

43. SABIN, A.B. - Oral poliovirus vaccine: recent results and recommendations for optimum use. Roy. Soc. Hlth. J., 82:51-8, 1962 .

44. SABIN, A.B. - Oral poliovirus vaccine. J. Amer. med. Ass., 194:872-6, 1965.

45. SABIN, A.B. et al. - Live, oraly given poliovirus vaccine: effects of rapid mass immunization on population under conditions of massive enteric infection with other viruses. $J$. Amer. med, Ass., 173:1521-6, 1960.

46. SABIN, A.B. et al. - Community-wide use of oral poliovirus vaccine: effectiveness of the Cincinnati Program. Amer. J. Dis. Child., 101:546-67, 1961.

47. SKOVRANEK, V. - Further observations in conjunction with the first field trial with live poliovirus vaccine in Czechoslovakia: epidemiological study. In: INTERNATIONAI, CONFERENCE ON LIVE POLIOVIRUS VACCINE. 2nd, Washington, D.C., 1960. Papers presented. Washington, D.C., Pan American 
BARBOSA, V. \& STEWIEN, K.E. - Estado imunitário relativo à polímielite das crianças de 0-12 anos, residentes no municipio de São Paulo, Brasil e assistidas pelo Hospital Menino Jesus. Rev. Saúde pübl., S. Paulo, 9:137-53, 1975.

Health Organization, 1960 . p. 507 21. (Scient. publ., 50)

48. SKOVRANEK, V. - Histoire de la lutte contre la poliomyélite en Tchecoslovaquie. Atti VII Congr. Int. Un. Med. Latina, p. 89-98, 1964 apud SABIN, A.B. Poliomyelitis: accomplishments of live virus vaccine. In: INTERNATIONAL CONFERENCE ON VACCINES AGAINST VIRAL AND RICKETTSIAL DISEASES OF MAN, 1st, Washington, D.C., 1966. Washington, D.C., Pan American Health Organization, 1967. p. 171-8

49. SUREAU, P. et al. - Deuxième campagne de vaccination antipoliomyélitique par voie orale effectué à Laghouat en 1966: II. Controôles virologiques et sérologiques de la vaccination. Arch. Inst. Pasteur Algér., 44:23-36, 1966.

50. SWARTZ, T.A. et al. - Routine admministration of oral polio vaccine in a subtropical area. Factors possibly influencing sero-conversion rates. J. Hyg., London, 70:719-26, 1972.

51. VERLINDE, J.D. \& WILTERDINK, J.B. - A small scale trial on vaccination and revaccination with live attenuated polioviruses in the $\mathrm{Ne}$ therlands. In: INTERNATIONAL CONFERENCE ON LIVE POLIOVIRUS VACCINES. $1^{\text {*t, }}$ Washington, D.C.. 1959. Papers presented.
Washington, D.C., Pan American Sanitary Bureau, 1959. p. 355-66. (Scient. publ., 44).

52. VOROSHILOVA, M.K. et al. - Virologic and serologic investigations of children immunized with trivalent live vaccine from A.B. Sabin's Strains. In: INTERNATIONAL CONFERENCE ON LIVE POLIOVIRUS VACCINES. 2:, Washington, D.C., 1960. Papers presented. Washington, D.C., Pan American Health Association, 1960. p. 240-65. (Scient. publ., 50).

53. WeINSTEIN, L. - Poliomyelitis: a persistent problem. New Engl. J. Med., $288: 370-2,1973$.

54. WESSLEN, T. \& EKELUND, H. - A small-scale trial of attenuated poliomyelitis vaccine. Acta. paediat., 48:428-42, 1959 .

55. WINTER, P.A.D. - Serological results of oral poliovaccine. S. Afr. med. J., 37:510-3, 1963.

56. ZACEK, K.J. - Serological surveys undertaken in connection with the natio-wide vaccination campaign against poliomyelitis in Cuba in 1962. J. Hyg. Epidem. Praha, 9:77-85, 1965.

Recebido para publicaçĩo em 17-03-1975 Aprovado para publicaçio em 04-04-1975 